\title{
Relato de experiência em um curso de extensão universitária: o consumidor frente a situações de decisão
}

\author{
Sérgio Candido de Gouveia Neto \\ Fundação Universidade Federal de Rondônia - Campus de Vilhena \\ sergio.gouveia@unir.br
}

Cristiane Talita Gromann de Gouveia

Universidade Estadual Paulista, Rio Claro/SP

thalita_hehe@hotmail.com

\section{Resumo}

O presente trabalho visa fazer um relato de experiência de um curso de extensão, realizado em 2011, com alunos dos cursos de Ciências Contábeis e Administração da Fundação Universidade Federal de Rondônia, Campus de Vilhena. O curso tinha como objetivo apresentar ferramentas da Matemática Financeira, além de discutir como e quais elementos matemáticos poderiam ser usados para tomada de decisão de comprar ou não um determinado produto. No curso, foram trabalhadas questões com as quais consumidores se deparam em lojas e/ou supermercados. As questões estavam dentro do modelo de ambientes de aprendizagem proposto por Skovsmose (2008), com referência aos cenários de investigação. Os resultados mostraram que os cursistas, no papel de consumidores, necessitaram mobilizar muitos elementos matemáticos em pouco tempo para decidir pela compra de um determinado produto.

Palavras-chave: Sociopolítica. Matemática. Modelagem.

\section{Experience report in a university outreach course: the consumer facing decision-making situations}

\begin{abstract}
The present work aims at elaborating an experience report of a university extension course, which took place in 2011, with undergraduate students of the Accounting and Administration courses of the Federal University of Rondônia - Vilhena - Campus. The course aimed to present the Financial Mathematics tools, besides to discuss how and what mathematical elements could be used for making the decision to buy or not a particular product. In the course, questions that customers face in shops and/or supermarkets were explored. The questions were within the model of the learning environments proposed by Skovsmose (2008), related to the scenarios of investigation. The results showed that the course participants, when in the role of consumers, needed to apply many mathematical elements in a short period of time in order to decide for the purchase of a certain product.
\end{abstract}

Keywords: Political Sociology. Mathematics. Mathematical modeling. 


\section{Considerações Iniciais}

Os sistemas de produção econômica, política e social sempre tiveram uma relação estreita com a Matemática. Por exemplo, a civilização egípcia desenvolveu uma matemática que permitia a distribuição de terras para o plantio nas margens do rio Nilo, com o objetivo de recolhimento de tributos (D’AMBRÓSIO, 2001). Em outras civilizações, o desenvolvimento dos calendários estava associado não apenas à questão do mito, do culto aos deuses, mas também ao desenvolvimento dos sistemas agrícolas, particularmente a agricultura, indicando a época certa do plantio e da colheita, com o objetivo de conseguir maior produção de grãos.

Atualmente, essa associação está bem próxima, e modelos matemáticos atuam em diversas situações do nosso dia a dia, definidos como Matemática em Ação (SKOVSMOSE, 2008). Esse autor afirma que "as inovações tecnológicas, os procedimentos econômicos, os processos de automação, o gerenciamento, a tomada de decisão" (SKOVSMOSE, 2008) constituem exemplos de Matemática em Ação. Nesses e em outros contextos, a matemática pode atuar como pano de fundo, sendo muito difícil perceber a sua ação e seus propósitos. Ainda segundo Skovsmose (2008, p. 12), "a ideia central é que muitas coisas podem ser realizadas quando a matemática está em jogo" e, para entender como essa ciência pode atuar em diversas situações, ele nos apresenta sete pontos:

1. Por meio da matemática, pode-se representar algo que não existe, identificando alternativas tecnológicas para uma dada situação;

2. A matemática proporciona a possibilidade de raciocínio hipotético, ou capacidade de analisar as consequências de um cenário imaginário;

3. A matemática pode ajudar na construção de justificativas, bem como de (falsas) legitimações de certas ações;

4. Implementação de rotinas, com a consequente mudança no nosso dia-a-dia;

5. Padronização através de algoritmos matemáticos em rotinas administrativas;

6. Autorização. Pode-se apelar para certas contas para justificar decisões e dar prosseguimento a determinadas tarefas;

7. Isenção de responsabilidade ética, baseada em estatísticas. (SKOVSMOSE, 2008 , p. $114-117)$

Assim, entender a Matemática em Ação pressupõe a realização de uma leitura crítica e reflexiva desses pontos de atuação. É nesse sentido que Skovsmose (2008) afirma ser necessário desenvolver uma Educação Matemática Crítica.

Essa Educação Matemática Crítica não é um ramo da Educação Matemática, mas uma atitude, uma preocupação em relação ao seu ensino. Skovsmose (2008, p. 16) afirma que a Educação Matemática Crítica "pode ser caracterizada em termos de diferentes preocupações”, sendo elas: fazer críticas da Matemática como parte da Educação Matemática, desenvolver uma educação matemática como suporte da democracia e, por fim, desenvolver a materacia ${ }^{l}$.

\footnotetext{
${ }^{1}$ Em alguns textos de Educação Matemática (SKOVSMOSE, 2008; D’AMBRÓSIO, 2001) encontram-se os termos materacia ou matemacia, mas todos se referindo a um mesmo conceito, de que trataremos logo a seguir. Entretanto, nas obras mais recentes, encontra-se o termo matemacia; assim, no decorrer deste texto, prevalecerá o uso desta expressão.
} 
O primeiro ponto constitui a crítica da Matemática como parte da Educação Matemática, no sentido da reflexão, questionando para que e por que são ensinados determinados tópicos dessa matéria na escola.

Já o segundo ponto da Educação Matemática Crítica se dá mediante o desenvolvimento de uma sociedade democrática, a partir de atitudes igualmente democráticas, pois, conforme Skovsmose (2008), a sala de aula atua como microssociedade, e atitudes democráticas nesses ambientes teriam reflexos em toda a sociedade. Entretanto, as aulas de Matemática são caracterizadas pelo monólogo do professor, pelos paradigmas do exercício, para os quais se tem apenas uma única resposta, fechados em si e que não permitem discutir situações da realidade. Romper essas situações é um dos objetivos da Educação Matemática Crítica, fortalecendo a democracia.

O terceiro ponto é o desenvolvimento da materacia. Para D’Ambrósio (2001, p. 67), a materacia é "a capacidade de interpretar e analisar sinais e códigos, de propor e utilizar modelos e simulações na vida cotidiana, de elaborar abstrações sobre representações do real [Instrumentos Analíticos]."

Skovsmose (2008, p. 16) complementa que a materacia "não se refere apenas a habilidades matemáticas, mas também à competência de interpretar e agir numa situação social e política estruturada pela matemática”. Baseando-se nessas definições, Biotto Filho (2008) faz uma importante interpretação da matemacia nos trabalhos de Skovsmose (2008), especificando que,

[...] inspirado por Paulo Freire e Ubiratan D'Ambrósio, Skovsmose (2001) entende matemacia como um conjunto de competências, que dividiremos em duas dimensões: técnica e sociopolítica. A dimensão técnica da matemacia envolve a habilidade de lidar com noções matemáticas, como reproduzir teoremas, demonstrações, dominar e construir algoritmos, conteúdos e raciocínios matemáticos. A dimensão sociopolítica da matemacia envolve aplicar tais noções em diferentes contextos e refletir sobre tais aplicações, avaliando o uso que se faz da Matemática. Caso a aplicação da Matemática não seja acompanhada de uma reflexão sobre suas implicações, então esta pode ser entendida estando associada a uma dimensão exclusivamente técnica. (BIOTTO FILHO, 2008, p. 14, grifos nossos)

Por meio dessas definições, trabalhar o ensino da Matemática numa abordagem da matemacia pode ajudar os alunos a entenderem e a refletirem sobre a atuação da matemática em ação na nossa sociedade. Mas, em sala de aula, como desenvolver a matemacia? A maioria das aulas de Matemática está associada apenas à dimensão técnica, sem reflexão ou, quando muito, com questões internas, sobre a estrutura da própria matemática (SKOVSMOSE, 2008).

Essas duas dimensões da matemacia (técnica e sociopolítica) podem encaixar-se nos ambientes de aprendizagem propostos pelo próprio Skovsmose (2006), como sinalizado no Quadro 1. Por exemplo, o professor de Matemática, ao trabalhar no paradigma do exercício em referência à matemática pura (1), está desenvolvendo o conceito técnico da matemacia. Mas os trabalhos de 
Skovsmose (2006 e 2008) mostram que os alunos adotam mais posturas reflexivas quando o professor se desloca para cenários investigativos ou, mesmo que fique no paradigma do exercício, o faça em outras referências ( 3 e 5), nas quais, a partir das reflexões, permitiriam o desenvolvimento da dimensão sociopolítica.

Assim, há uma possibilidade de, ao movimentar-se dentro desses ambientes de aprendizagem, desenvolver-se a matemacia. Trabalhar somente no paradigma do exercício, com referências à matemática pura (1) torna muito difícil discutir questões sociopolíticas; porém, mudar algumas vezes para outros ambientes, principalmente relacionados à realidade, pode fazer emergir situações que favoreçam o desenvolvimento dessa dimensão, ao propiciar o surgimento de elementos reflexivos, bem como de elementos dialógicos (SKOVSMOSE, 2008).

Quadro 1 - Ambientes de aprendizagem

\begin{tabular}{|l|c|c|}
\hline & Paradigma do exercício & Cenário para investigação \\
\hline Referências à matemática pura & 1 & 2 \\
\hline Referências à semirrealidade & 3 & 4 \\
\hline Referências à realidade & 5 & 6 \\
\hline
\end{tabular}

Fonte: Skovsmose, 2000.

A compra de um determinado produto em um supermercado ou em uma loja de eletrodomésticos oferece oportunidade de situações que podem ser usadas em sala de aula para discutir a ação da matemática em nossa sociedade, principalmente o seu uso pelas estruturas de poder econômico. Por exemplo, as empresas perceberam que podem usar diferentes unidades de medidas para um mesmo produto, associadas, obviamente, a diferentes preços. Nessa situação, o consumidor, ao entrar em um supermercado, depara-se com situações em que é preciso tomar uma decisão: Qual produto comprar? Qual a opção mais vantajosa? Aqui, a pessoa necessita mobilizar conhecimentos matemáticos em pouco tempo para optar entre comprar ou não determinado produto.

Neste trabalho, serão usadas situações relacionadas ao consumidor. Comprar ou não determinado produto é uma situação que envolve alguns aspectos da matemática em ação, tais como, o que estou comprando é suficiente para a família toda? (capacidade de analisar as consequências de um cenário imaginário). Envolve, também, questões sociopolíticas: com o que ganho, quanto é possível comprar? Por que o que ganho não é suficiente? Quais as melhores opções de compra, de forma que eu possa comprar mais produtos? A relação preço e peso são proporcionais? Como decidir pela melhor compra?

Portanto, o intuito é tentar entender um pouco sobre os mecanismos e ferramentas matemáticas a serem utilizados pelos consumidores no momento de decidir sobre adquirir ou não um determinado produto. 
Por fim, destacamos que a ideia do curso surgiu a partir do Projeto de Extensão "Educação Matemática e Financeira”, desenvolvido na Fundação Universidade Federal de Rondônia Campus de Vilhena - e das discussões da disciplina de doutorado "Aprendizagem Matemática", ministrada pela Professora Dr. ${ }^{a}$ Miriam Godoy Penteado, no mês de janeiro de 2011, na UNESP Rio Claro - como parte das atividades do Doutorado Interinstitucional em Educação Matemática (UNIR/UNESP), cursada pelo primeiro autor.

O Projeto de Extensão era composto pelos cursos de "Matemática Financeira Básica", "Matemática e Calculadora Financeira" e "Gestão Orçamentária Familiar", com cargas horárias de 20 horas. Essa ação de extensão foi apresentada como parte de um trabalho da disciplina da Professora Miriam, que motivou um debate sobre se bastava saber matemática financeira para conseguir tomar uma decisão de comprar ou não um determinado produto. Por meio dessas discussões, resolvemos ampliar o projeto de extensão com o curso "Educação Matemática do Consumidor", mas com o arcabouço teórico, apresentado neste texto, com carga horária de 20 horas.

\section{Considerações Metodológicas}

Neste trabalho, adotamos uma abordagem qualitativa. Foram feitas observações e anotações pelos professores das atividades e das opiniões e reações dos alunos. Além disso, os alunos fizeram relatório de suas próprias atividades. Esses materiais constituíram fontes de análise.

O curso de extensão foi desenvolvido numa sala de aula da Fundação Universidade Federal de Rondônia - Campus de Vilhena - no período de 21 a 25 de março de 2011. Foram abertas 30 vagas, que deveriam ser preenchidas pelos primeiros inscritos, mas apenas 10 acadêmicos dos cursos de Ciências Contábeis e Administração inscreveram-se para o curso.

Nos três primeiros dias, trabalhamos com uma abordagem ao paradigma do exercício com referência à matemática pura, cujo objetivo era verificar se os alunos utilizariam esses conhecimentos quando estivessem trabalhando em cenários investigativos com referência à realidade. Os assuntos abordados foram porcentagens, juros simples e descontos simples, os quais foram tratados da forma tradicional, ou seja, as aulas se processavam da seguinte forma: discutiamse os conceitos, aplicavam-se exemplos e exercícios e, em seguida, fazia-se a correção. Destacamos que o material didático utilizado foi o quadro negro e os alunos ocupavam carteiras dispostas em fila.

No quarto dia, foram utilizadas algumas questões-desafio (Figura 1) propostas aos alunos pelos professores. De acordo com Skovsmose (2008, p. 62), “questões-desafio são importantes para facilitar e provocar reflexões, tanto reflexões sobre matemática quanto sobre, digamos, 
confiabilidade e responsabilidade". As questões-desafio tinham o objetivo de agir como um mecanismo disparador de situações que acontecem no cotidiano dos alunos.

Inicialmente, duas questões-desafio foram colocadas pelos alunos: a compra de uma solução antisséptica bucal e de um achocolatado. Para a solução antisséptica bucal, existem no mercado dois tamanhos de frascos, sendo um de $250 \mathrm{ml}$ e outro de $500 \mathrm{ml}$. Para o achocolatado existem também dois tamanhos, um de $200 \mathrm{~g}$ e outro de $800 \mathrm{~g}$. Outra questão apresentada foi sobre qual seria a melhor opção para comprar uma TV: à vista, a prazo em seis ou doze vezes ou colocar o dinheiro na poupança, com uma taxa de $0,65 \%$ ao mês. A partir do desenvolvimento e aplicações das questões-desafio, os alunos formaram três grupos, sendo dois deles com três acadêmicos e um com quatro.

No último dia, os acadêmicos trouxeram a questão da compra de papel higiênico. Comprar papel higiênico envolve a escolha de diversas marcas, com tamanhos diferentes (20, 30, 40, 50, 60, 80 e 90 metros) e quantidade de rolos diferentes por pacote (2, 4, 6, 8, 12 e 16 rolos), qualidade de papel (mais ou menos macios), reciclados ou não. Diante dessa situação, para o aluno no papel de consumidor, qual é a melhor opção de compra? De quais ferramentas matemáticas o aluno, no papel de consumidor, necessita para decidir pela melhor compra desses produtos?

\section{Resultados e Discussões}

A dimensão técnica da Matemacia: desenvolvendo modelos para resolver situações no contexto do consumidor

Considerando a dimensão técnica da Matemacia no curso de extensão, notamos que, aparentemente, os cursistas mobilizaram conhecimentos matemáticos básicos na resolução das questões-desafio. Por conhecimentos matemáticos básicos, estamos entendendo operações de adição, subtração, multiplicação e divisão. Contudo, observando melhor os resultados, notamos que, se um problema apresenta um nível maior de complexidade, como por exemplo, no caso do papel higiênico (Figura 1), os cursistas desenvolveram modelos mais avançados, com a utilização de tabelas, subdividindoos em unidades.

Notamos que a primeira parte do curso, na qual foram tratadas questões baseadas no paradigma do exercício com referência à matemática pura, com assuntos sobre porcentagens, juros simples e descontos simples - essas informações não foram utilizadas nas resoluções das questões desafio, possivelmente, nesse tipo de problema não teria sido necessário mobilizar tais tópicos. Mas, como uma das funções da Educação Matemática Crítica, podemos questionar se esses assuntos seriam importantes na resolução de problemas dessa natureza. 
Figura 1 - Questões-desafio propostas aos/pelos alunos

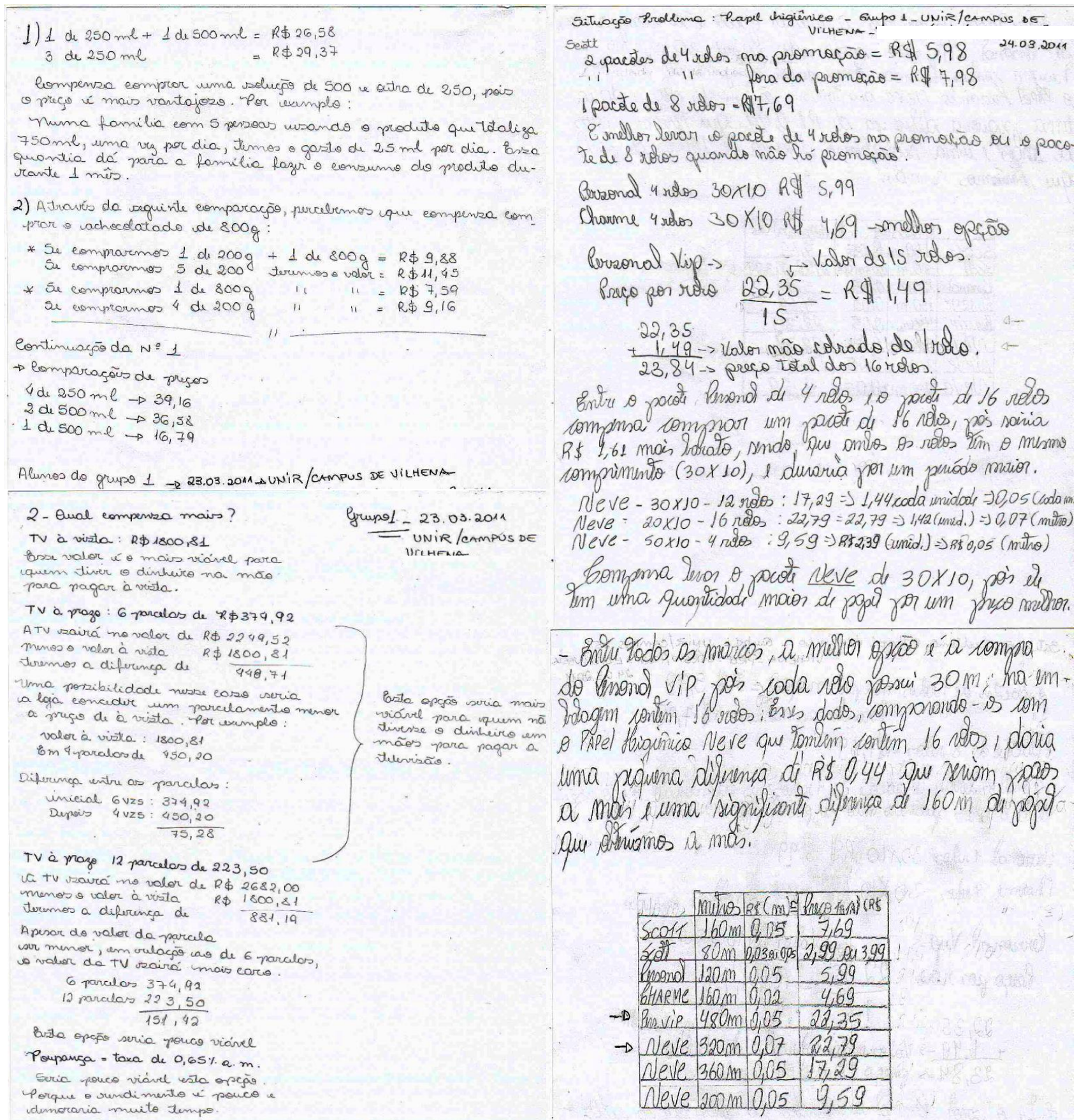

Fonte: Dados do Projeto de Extensão.

\section{A dimensão sociopolítica da Matemacia: questionando as estratégias das empresas}

Durante o desenvolvimento das atividades aplicadas com questões abertas, surgiu uma discussão sobre a escolha que o consumidor realiza durante a compra de um produto, influenciado, principalmente, pelo valor de dinheiro que ele tem disponível. Essa discussão dos cursistas nos fez pensar que pode ser uma estratégia das empresas, que colocam uma diversidade de produtos com preços diferentes, buscando atingir assim diferentes públicos. 
Por um lado, pensamos que essa seja uma resposta para o fato de que produtos menores, em sua maioria, tenham preços relativamente maiores. Por outro lado, as empresas podem estar visando o consumidor que não possui dinheiro disponível para comprar o produto de maior quantidade, pois, mesmo que em relação à unidade ele seja mais barato, devido ao tamanho/quantidade do produto, o valor é maior, o que não dá muitas alternativas ao consumidor, a não ser comprar o produto menor, mesmo pagando relativamente mais caro por ele.

$\mathrm{Na}$ resolução da questão sobre a solução bucal, alguns cursistas levantaram questionamentos afirmando que a escolha seria influenciada também pelo consumo e não somente pelo preço (Grupo 1). Além dessas estratégias de oferecer produtos em diferentes quantidades, os cursistas (Grupo 1) conversaram sobre outras possibilidades utilizadas pelos supermercados, principalmente as de oferecer produtos em ofertas, ou 1 (um) dia na semana de desconto para determinados produtos. O grupo ressaltou que, quando os supermercados oferecem produtos em ofertas num dia específico, por exemplo, numa terça-feira, apenas alguns produtos entram em oferta, mas a grande maioria não. Nesse caso, o consumidor vai "iludido" pelas ofertas e acaba comprando outros produtos que não estavam em oferta, não percebendo que assim acaba perdendo todo o valor do desconto.

Por fim, foi perguntado aos cursistas quais os sentimentos deles diante dessas situações e questionamentos apresentados, os quais responderam que se sentiam frustrados e impotentes.

\section{Considerações Finais}

Acreditamos que a utilização, em sala de aula, de questões relacionadas ao consumo pode potencializar discussões sobre a dimensão sociopolítica da Matemática, ao abrir a possibilidade de abordar temas relacionados ao direito do consumidor, ao questionar o papel das propagandas e, principalmente, ao entender um pouco das estratégias utilizadas pelas empresas na venda de seus produtos. Contudo, há um sentimento de incapacidade do aluno como consumidor frente a tais questões.

O desenvolvimento da dimensão técnica da Matemática mostrou que as diferentes medidas dos produtos, ao invés de ajudar, simplesmente tornam mais difíceis a escolha por um determinado produto. Ao decidir pela compra ou não daquele produto, o consumidor necessita mobilizar diversos conhecimentos matemáticos (organização de dados em tabelas, multiplicação, divisão, adição, etc.), tudo isso em pouco tempo.

Entretanto, considerando uma sala de aula, a utilização dessas questões pelo professor pode abrir possibilidades de romper com o paradigma do exercício - quase sempre fixado em um único modelo de resolução - ao juntar diversos conteúdos em uma questão referente ao dia a dia do aluno. 
Apesar desses pontos, ressaltamos que a experiência de ensino aqui apresentada foi desenvolvida com alunos em um curso de extensão universitária. Assim, deixamos como possibilidades de trabalhos futuros a aplicação dessas questões-desafio em outros cursos.

\section{Referências}

ALR Ø, H.; SKOVSMOSE, O. Diálogo e Aprendizagem em Educação Matemática. Trad. Orlando de A. Figueiredo. Belo Horizonte, MG: Autêntica, 2006. 160 p.

BIOTTO FILHO, D. O desenvolvimento da matemacia no trabalho com projetos. Dissertação (Mestrado em Educação Matemática) - Universidade Estadual Paulista, Instituto de Geociências e Ciências Exatas - UNESP - Rio Claro. Rio Claro, SP, 2008.

D’AMBRÓSIO, U. Etnomatemática: elo entre as tradições e a modernidade. Belo Horizonte, MG: Autêntica, 2001. 110 p.

SKOVSMOSE, O. Cenários para investigação. Trad. de Jonei Cerqueira Barbosa. Bolema Boletim de Educação Matemática, Rio Claro, n. 14, p.66-91, 2000.

SKOVSMOSE, O. Desafios da Reflexão em Educação Matemática Crítica. Trad. Orlando de A. Figueiredo, Jonei Cerqueira Barbosa. Campinas, SP: Papirus, 2008 - (Coleção Perspectivas em Educação Matemática). 147 p. 